\title{
Bormort.
}

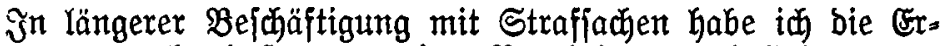

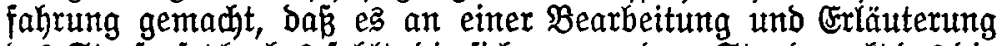
Des Strafgejekbuches fehlt, die fich - von dem Standpunt bes bie Bedürfniffe und Mängel wahrnehmenden $\mathfrak{X}$ uffichtsbeamten aus -

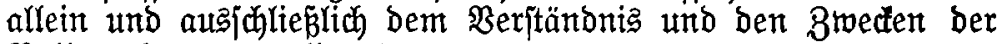
Bollzugăbeamten wiomet.

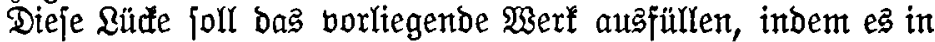
fnapper, aber boch bis zum bollen Berjtänonis durdygefühthten Form alles bas zu bringen verjucht, wả bie genannten Beamten braudhen, um, auch auf fich allein angerwiejen, ihrem $\mathfrak{B}$ eruf mit ber nötigen Bejejeghenntmis aubgerüftet nachgeben zu fönnen.

Die Bentbung ift in folgenter $\mathfrak{A r t}$ gebacht: Die Erräuterungen jolfen ber erfen $\mathfrak{u}$ nterweijung in ben Srhumanns= und Ben= barmeriejaulen zugrumbe gelegt werden fömen und ipäter ber eigenen pribaten fortbildung bes einzelnen bienten. Banz be= jonders aber follen fie bon ben Beamten, wenn bie Beit zureicht, jeweiłs bei $\mathfrak{U}$ ufnahme von $\mathfrak{A}$ nzeigen und vor Cryebung eitter beftimmten Sache nochmałs buragelejen werben, $\mathfrak{u m}$ an $b a \mathfrak{s}$ Wejentliche zu erinnern und umötige jowie in falfuher Ridytung ausgeführte Ermittelungen zu berhindern.

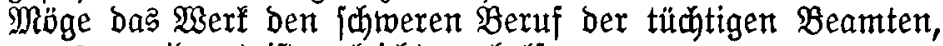
benen ę gerwiomet ift, erleidjtern helfent.

Sf fen $\mathfrak{b u r g}$ (Baben) im $\mathfrak{A}$ uguft 1907.

\section{Dr. (órojd.}

\section{Borwort zux zehnten $\mathfrak{A} \mathfrak{u f l a g e .}$}

Der $\mathfrak{B e r l a g}$ ift nach bem Tobe bes Randgeridjtapräjibenten Dr. (Brojich mit ber Bitte an mich herangetreten, die Bearbeitung ber 10. 2luflage zu übernehment.

Diejem $\mathfrak{B}$ uniche bin idh gerne gefolgt.

Dabei habe id midh bon Dem Bejtreben Ieiten laffen, vharafter

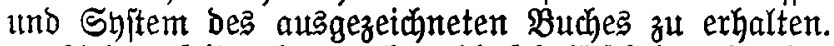

Unbererjeits aber madten bie feit Grjheinen ber lebten $\mathfrak{A}$ uflage

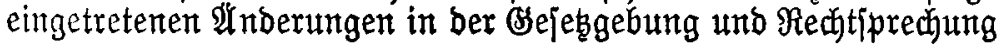

